\title{
A Theoretical Examination of Double Jeopardy: Using Theory as Guide to Concept Analysis
}

1979 "Critical Dimensions of Children's Literature: The Suppression of Conflict and Self." Red Feather: The Red Feather Institute.

Young, T. R., and Garth Massey

1977 "The Dramaturgical Society: A Macro-Analytic Approach to Dramaturgical Analysis." Qualitative Sociology. 1:78-98.

\section{Richard Coon \\ Carroll College}

Mid-American Review of Sociology, 1986, Vol. XI, No. 1:

This article is a theoretical examination of the validity of the double jeopardy hypothesis from a number of social psychological perspectives. After a general review of the literature on double jeopardy, section two sets forth some alternative views on minority aging. In section three, four social psychological theories are explicated in order to ascertain whether they would predict a double jeopardy outcome. In no case does the prediction suggest double jeopardy. Finally, a caveat is noted regarding how researchers define double jeopardy.

\section{INTRODUCTION}

The purpose of this treatise is to critically evaluate the merit of the concept of "double jeopardy" as regards minority aged. In order to accomplish this, I review the literature on double jeopardy in an attempt to depict the tenor of much of the research in the field. This review is structured around five variables which have been used in earlier investigations of double jeopardy.

In section two a reevaluation of the concept is carried out by looking at some alternative research findings which do not support the double jeopardy concept. Also, in this section an attempt is made to ground the formulation of the double jeopardy notion within a general historical perspective. This temporal analysis is underpinned by a diagrammatic representation of the growth of the double jeopardy concept. Finally, a discussion of numerous theoretical perspectives and their relationship to double jeopardy is presented. No one theory is considered most important, but rather, each theory is presented as adding insight into the understanding of the concept. 


\section{THE CONCEPT OF "DOUBLE JEOPARDY"}

Over the past few decades, research on the elderly has become more prominent in a number of scientific disciplines. Until recently, however, the vast majority of these investigations has been limited to the aging of whites. Recent studies have begun to rectify this situation, although much must still be done to bring about a better understanding of the condition of the minority elderly.

One of the current concepts to grow out of this recent interest in studying nonwhite elderly populations is that of "double jeopardy" (Dowd and Bengtson, 1978; Palmore and Manton, 1973; Jackson, 1972). As observed by Dowd and Bengtson (1978:427), the "plight of minority aged has been characterized by many as one of double jeopardy." In addition to disadvantages imposed by their minority group status, minority aged are said to experience the devaluation in status associated with old age. Hence, when one is in double jeopardy, one has associated with him/herself two statuses which are negatively valued by society. Further, Ward (1979) has suggested that these two negative statuses have a multiplicative interaction which worsens the situation of the status incumbent.

One of the tasks of this study is to critically review the literature in the area of aging related to the concept of double jeopardy. This review is carried out by noting five areas of interest relative to this topic: (1) education, (2) family, (3) employment, (4) income, and (5) health related issues.

\section{Education}

In general, aged Blacks are less well-educated than aged Whites. In.1964, the National Urban League offered the argument that lower education for older Blacks results in a "vicious circle." Low education means lower skilled labor potential and unsteady, part-time, low paying jobs. Hence, there are often either no social security benefits or very small social security benefits because of extremely low past earnings.

Table 1 presents evidence drawn from the work of Jackson (1974), which she used to indicate that as of 1970 minority aged had a lower mean level of education, regardless of sex. Whites are reported to have had at least an eighth grade education, whereas no minority group achieved this level. Aggregating these data across both sex and age categories, the mean level of education for Blacks was 6.08 years of schooling, for Spanish 5.73 years, and for Whites 8.85 years of formal education.
Table 1. Median number of years of education ${ }^{a}$

\begin{tabular}{lccc}
\hline & Black & Spanish & White \\
\hline Female & & & \\
65-69 years of age & 7.0 & 6.2 & 9.5 \\
$70-74$ years of age & 6.7 & 5.9 & 8.9 \\
$75+$ years of age & 6.1 & 5.4 & 8.7 \\
Male & & & \\
65-69 years of age & 6.0 & 6.1 & 8.9 \\
$70-74$ years of age & 5.6 & 5.9 & 8.7 \\
$75+$ years of age & 5.1 & 4.9 & 8.4 \\
\hline
\end{tabular}

aSource: U.S. Bureau of Census, 1970. (Quoted in Jackson, 1974:146).

As of 1980, Harris and Cole reported that the level of education still differs markedly between Whites and Blacks. In 1977, 38 percent of white males and 41 percent of White females who were 65 years of age or over had at least a high school education. For Blacks, however, only 16 percent of the males and 14 percent of the females had a high school diploma. Further, they note that the level of educational attainment of MexicanAmericans is even worse. As of 1976, for Mexican-Americans 65 years of age and over, 70 percent of the females and 64 percent of the males had completed less than 5 years of formal education. Only 4 percent of older Mexican-American males have completed a high school education.

Family

In 1964, the National Urban League posited the notion that due to extremely poor wages, more Black men than White men never marry. Thus, they face the prospect of retirement alone, with no help from wife or children. In 1974, Jackson argued that this pattern was still the case for the elderly Black male.

Dowd and Bengtson (1978) have avered that the family is an important life resource for the minority aged. This is said to be the case because they are frequently in contact with other family members. ${ }^{1}$ Kalish (1975), as well as Ragan (1978), argue against this notion of family as a resource for minority elders. For instance, Kalish (1975:19-29) points out that: 
It is a common assumption, perhaps with some basis in truth, that blacks and other minority group members offer greater acceptance to their elderly and that both the older minority members and their families prefer that they remain within the home. This assumption has been attacked in recent years as an excuse on the part of the "white establishment" for not providing adequate long-term care facilities for non whites. The claim is made that nonwhites are underrepresented in these care facilities because of overt racial discrimination and because of serious economic limitations.

Beyond this, if Dowd and Bengtson are correct and "frequence of contact with children" is a buffer against the vicissitudes and anguish of old age, why does Ragan (1978) indicate that Mexican-American women (an ethnic group said to be very family oriented) are the most unhappy category in her research sample? Is this a mere anomaly or are there other, unseen factors? The following is an extensive quote from her report:

It is frequently suggested that older Mexican-Americans may enjoy some of the advantages of aging in a more traditional subculture in which elders are honored and strong family ties provide emotional support. In contrast, out of all the race-by-sex categories in our sample, it was the Mexican-American women (45-75) who were the unhappiest. More than any other group, they reported feelings of sadness, and that life is hard. The empty nest period in the lives of women is often discussed in terms of loss and adjustment, although those assumptions are under reexamination. The corollary assumption is that women in an environment in which important motherly roles are not interrupted will show fewer problems of adjustment. We found that the Mexican-American women in our sample indeed were much more likely to have a child under 18 in the home with them ... Mexican-American women in this age group have had more children and have continued to bear them at later ages, so some of the young children still in the home were the women's own children, but about one-half of these 'full nests' were so defined by the presence of other children, such as grandchildren, nieces, nephews, and children of relatives and friends. The Mexican-American women were not happier than the white women, and were somewhat less happy in certain respects; there was no clear association between the empty nest and morale in these two groups. The highest percentage of MexicanAmerican women reporting that they felt less useful as they grew older was actually found among those older (65-75) women with a child in the home (1978:2-3).

Ragan's work implies that there are factors involved in one's family relations other than mere proximity. Family proximity my be the result of a number of underlying causes. Poverty, due to discrimination for example,

may make family mobility impossible, thus adding a strain to an elder's already meager income. Hence, without further analysis, it is difficult to say whether close family proximity is a resource or a liability for minority aged.

\section{Employment}

Table 2 presents the 1970 employment statuses of Blacks, Spanish, and Whites in the United States. In spite of the relative similarities in percent of working individuals, there remains a great disparity in the type of work performed by those individuals. As Jackson (1974) notes, the modal male occupation in the United States is craftsman and kindred worker followed by service worker. For Black men, though, service work is the modal occupation; only 13.6 percent of Blacks worked as craftsman or kindered workers. "Scanty or inferior education, fewer job opportunities, less steady work, a high rate of unemployment and low pay scales make inevitable the insecurity and poverty of aging Negroes" (National Urban League, 1964:13).

Table 2. Employment status, by percent ${ }^{\mathrm{a}}$

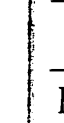

\begin{tabular}{|lrrr}
\hline & Black & Spanish & White \\
\hline Female, 65+ years of age & & & \\
in labor force & 13.2 & 7.9 & 9.8 \\
full-time civilian labor f. & 41.6 & 58.1 & 49.0 \\
part-time civilian labor f. & 48.6 & 30.9 & 41.5 \\
unemployed civilian labor f. & 5.1 & 7.0 & 5.0 \\
Male, 65+ years of age & & & \\
in labor force & 23.5 & 24.8 & $24: 9$ \\
full-time civilian labor f. & 56.6 & 62.7 & 56.9 \\
part-time civilian labor f. & 33.7 & 26.9 & 34.7 \\
unemployed civilian labor f. & 5.6 & 6.4 & 4.3 \\
\hline
\end{tabular}

aSource: U.S. Bureau of the Census, 1970. (Quoted in Jackson, 1974:147)

Income

Table 3 demonstrates the difference in income for minority and White aged. Both older Black and Mexican-Americans have a much lower income level than their White counterparts (Dowd and Bengtson, 1978). Not only do minorities start with lower incomes, they also have a much greater decline in wages over a 30 year span. In Dowd and Bengtson's (1978) research, there 
was a 55 percent decline in wages for Blacks across the three age categories and a 62 percent decline for Mexican-Americans. For Whites at the lowest income level, income was still nearly double that of either Blacks or MexicanAmericans.

Table 3. Income characteristics ${ }^{a}$

Black Spanish White

Median individual income

\section{Female}

65-69 years of age

70-74 years of age

$75+$ years of age

$$
\$ 1,170
$$

$\$ 1,270$

1,248

1,189

$\$ 2,594$

2,305

2,032

Male

$65-69$ years of age

$70-74$ years of age

1,956

2,659

5,959

$75+$ years of age

1,711

2,101

4,630

1,503

1,738

3,621

aSource: U.S. Bureau of the Census, 1970. (Quoted in Jackson, 1974:148-9).

Jackson (1974) points out that an income gap between Black and White elders is now greater than it has previously been. The lowest income stratum usually is Black females, a situation that is complicated by the fact that Black females, in many instances, are family heads.

Both Jackson (1974) and the National Urban League (1964) suggest that even when education is controlled, there is still a radical divergence between even when education is controlled, there, the mean difference between Black and White female college graduates in 1969 was $\$ 1,729$. ." Jackson, 1974:147).

Robert Hill (1978) points out that Black families whose household head is 65 years of age or over have a much lower income level than White families whose household head is 65 or older. "The median income for elderly whose household wife Black families in 1976 was $\$ 6,457$, whereas the median income of similar White families was $\$ 8,902 "(1978: 4-5)$. Harris and Cole (1980) come of similar White families was $\$ 8,902$ (ith Mexican-American aged.

\section{Health related issues}

Dowd and Bengtson (1978) report that minority aged feel they are in poorer health than Whites. They note also that minority aged reported more ill health with increasing age. This also is true for White aged, although the increase is not as significant. Thus, at each age stratum $(45-54,55-64$, 65-74) the self-perceived health of minority aged is poorer than that of Whites, with the disparity occuring among those 65 years of age and over.

They go on to suggest that as racial or ethnic groups age their life expectancy becomes more similar to that of Whites. Although minority group mortality begins to converge with that of Whites, subjectively, minority members do not seem to align their self-perceptions with this objective fact. Jackson (1974) posits that this convergence may be due to the operation of "survival of the fittest" among Blacks.

Cooper and Simonin (1978) investigated attitudes toward death and found that Mexican-Americans and Blacks, aged 45-54, were more afraid of death than Whites, while Mexican-Americans and Blacks, aged 65-74, were less afraid than Whites. One possible reason for the difference in atti tudes toward death held by old minority members is that they may feel they have accomplished a great deal simply by reaching an advanced age. As Ragan (1978:4) emphasized, one "can appreciate this expression of having survived to old age against greater odds than most of us face." Hence, their feelings of accomplishment help to buffer their fear of dying. Marshall (1976) noted a similar finding in his investigation of aged minorities.

Bengtson (1977) indicates that both Mexican-Americans and Blacks define themselves as old well before Whites do. Over 30 percent of MexicanAmericans studied by Bengtson indicated that they defined themselves as. old by the age of 63; Whites, on the other hand, did not define themselves as old until nearly age 70 . Jackson (1970) points out that this sort of early identification with old age may be due to the hardships with which minority members have to deal throughout their lives. One might think of this as relating to the common sense notion that people "educated in the school of hard knocks" grow up faster.

As indicated by the data reviewed, minority aged find themselves in an unenviable predicament. Due to discrimination, it is argued that they have fewer resources in old age and thus many find themselves in a position of dependence. However, this is not to say that the data presented above are necessarily supportive of the multiplicative notion of double jeopardy. Rather, it may only demonstrate that discrimination towards minorities is widespread in our society at all points of the life span. Or, it may be that 
some areas of minority members' lives are more affected by negative status than are others, thus producing double jeopardy in one facet of the individual's life but not in another. We, for example, might conject that the sphere of objective characteristics might more readily produce such outcomes. Yet, we tend to find that research using variables which are objective in nature produce varied findings. Hence, even predicting double jeopardy at this very abstract level is quite problematic. It is because of this uncertainty that further research in this area is needed.

Although minority members are discriminated against in old age, this does not necessarily mean they are discriminated against moreso as they get older as the mulitplicative model would suggest. In fact, some have submitted (Dowd and Bengtson, 1978; Kent, 1971; Pampel, 1981) that age may act as a leveler.

As Chappell and Havens (1980) have pointed out, double jeopardy may well not exist in a unidimensional form as seems to be implied in the extant literature. There would appear to be at least two dimensions to this concept; specifically, an objective element and a more (social psychological) subjective element. An important issue to be explored here is whether this hypothesized objective loss said to characterize the elderly minority member may be balanced by subjective elements.

Furthermore, the data marshalled with respect to double jeopardy have at times appeared to be contradictory. Dowd and Bengtson (1978) indicate that the minority family is closely knit and serves to insulate the aging from the loss of status due to old age. Moore (1971) also comments on the coping function of the minority family. Yet, Ragan (1978) notes that there are a number of factors which bear on the situation that must be considered before we are able to make any hard and fast statements about family relations acting as a buffer for the minority aged. Seelbach (1978) and Jackson (1972) both argue that race does not seem to be a significant determinant of family structure, denoting instead the importance of class as a determinant of family relations.

\section{SOME ALTERNATIVE VIEWS ON MINORITY AGING}

Within the recent past, a number of investigations have presented evidence which leads one to question the validity of double jeopardy. For instance, Neugarten and Moore (1968) observe that Rose, as early as 1962 had argued for the notion that age acts as a leveler with respect to diverse status characteristics. They suggest that retirement communities produce subcultures in which the age status overrides all other statuses, such that, "social class, sex, and ethnic considerations play less role in the social relationships of the inhabitants..." (1968:21). Dowd and Bengtson (1978) also indicate that in certain respects age may act as a leveler when they point out that "(V)ariables such as frequency of interaction with relatives as well as, for black respondents, the life satisfaction factors of tranquility and optimism all evidence a certain decline in the extent of ethnic variation across age strata" (1978:434). Moore (1971:89), also states that for minorities "... in almost all cases (whether in reservation, ghetto, or barrio) substructures have developed, and have often been institutionalized, that could very loosely be termed 'coping structure'." This notion of coping refers to several issues, such as, helping to meet survival needs, means of social participation, foundations of prestige and power, and the simple fact of a feeling of belonging to some type of collectivity or group (Moore, 1971).

Elam (1970) has also suggested that the upsurge in minority self-pride may improve the chances of the minority elder reaching a position of ego integrity. This (the recent restructuring of black pride) reevaluation of the past may provide Blacks with more positive integrity support than would be the case for the nonminority elder. Kent (1971) has also argued that age offsets racial difference due to the exigencies of survival in old age. Hence, the immensity of the problems in old age pale the issues of racial differentiation.

Further, recent research by Ward (1979) has indicated that age seems to have little or no impact on the relative status of Blacks as compared to Whites. Ward (1979:14) reports that

"(T)his research found racial differences on a variety of dimensions to be comparatively" small in all three age groups once the socioeconomic consequences of race were controlled, supporting Jackson and Walls' (1978) contention that socioeconomic controls show that 'the significant differences between aged blacks and whites typically stressed by advocates for aged blacks are largely myths"' (p. 112).

Taking these investigations into consideration, it is plain to see that the integrity of the double jeopardy concept is being brought into question. One of the pressing needs in the double jeopardy literature is to place the notion within a larger frame of reference and begin to articulate those instances (scope conditions) that do or do not produce double jeopardy outcomes. The main task of this treatise is to partially fill this need by placing the construct within several frames of reference so as to denote how these 
different theory structures correspond to double jeopardy. This should allow us to better understand what it is we are investigating and thereby help us to ask well-informed questions and carry out more complete research. As depicted in Diagram 1, from the introduction of the concept, the National Urban League implied that there was an interactive relationship between the statuses of age and race and that this interaction resulted in a negative outcome. This postulate was then investigated by Jackson $(1972,1974)$ and Palmore and Manton (1973) by studying the objective differences between minority members and nonminority members with cross-sectional data. Although the data upheld the suggestion of racial differentiation, the research on the concept did not stop there. Others, such as Dowd and Bengtson (1978) reported findings of racial differences but began to question the adequacy of the concept as a unidimensional construct. Even before this, numerous other researchers (such as, Kent and others discussed above) began to point toward other interpretations of the effects of aging in minority populations. However, the Dowd and Bengtson (1978) piece is especially important because of the prominence of the authors in the field of gerontology.

With the diversity of research finding, an implicit reevaluation of double jeopardy has begun to take place. Jackson and Walls (1978) assert that double jeopardy may be a myth, albeit a myth which Jackson had earlier fostered. Moreover, Ward (1979) posits no effect of age-race interaction. Diagram 2 illustrates that the research is becoming more sophisticated and well-informed with each additional step. Present research is at the point of looking at both objective and subjective levels and entertaining a variety of alternative explanations of minority aging. As portrayed in Diagram 3, we can formulate three alternatives hypotheses about age-race interaction.

Even with this growing sophistication, however, most investigators still have not used theory to guide their research program, using only empirical generalizations as a guide to further research. It will be asserted here that this is a real weakness of the "double jeopardy" literature. Hence, one of the major contributions of this paper will be to look at some of the possible implications certain social psychological theories offer in regard to the interaction of multiple statuses.

\section{THEORETICAL IMPLICATIONS}

It needs to be made clear that this paper is not intended to be a test of any of the following theories. Rather, each of the frameworks is depicted
A Theoretical Examination of Double Jeopardy

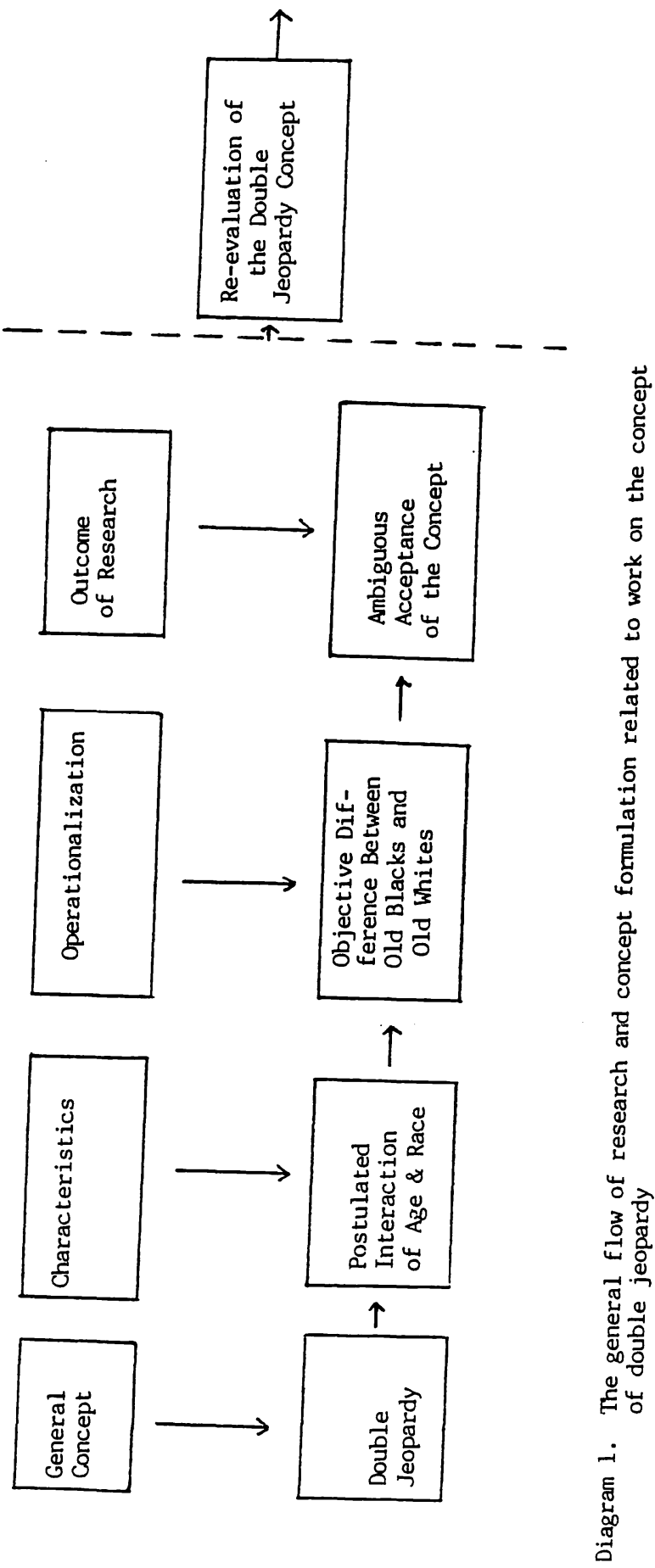




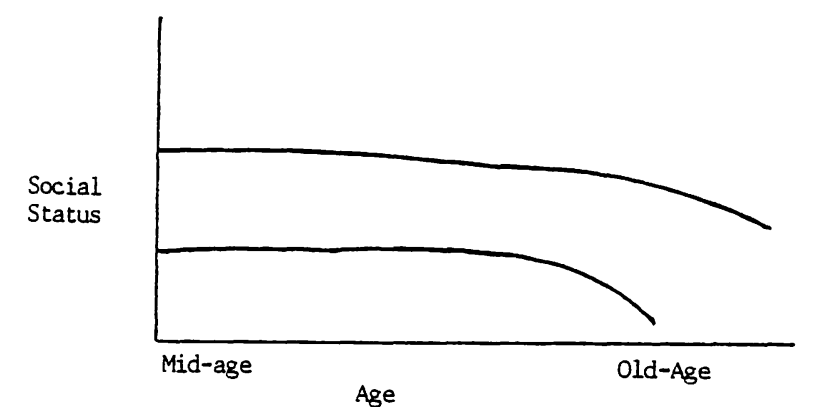

DOUBLE JEOPARDY negative status interaction

Age

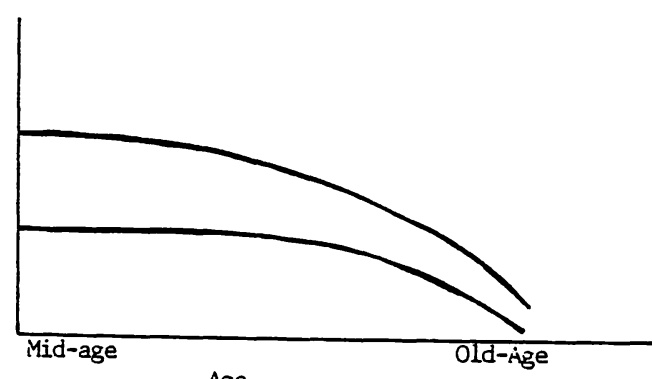

Age

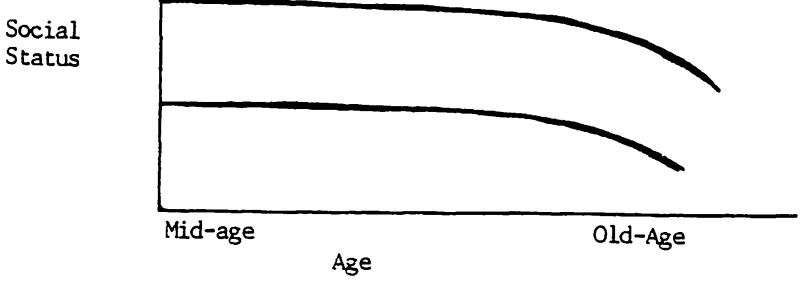

Diagram 3. Three alternative hypotheses which are to be investigated in this research
AGE AS LEVEIER

age as master

status masks effect

of race

NO INTERACTION race as master status masks effect of age

as simply adding direction to the investigation of double jeopardy. The theories to be drawn upon here are as follows: 1) status inconsistency; 2) social learning-exchange theory; and 3) status generalization theory.

\section{Status inconsistency}

Status inconsistency has been referred to by numerous author (Hughes, 1945; Lenski, 1954; Homans, 1974; Geschwender, 1967; Lebowitz, 1975; and others). As stated by Strieb (1976:181) "(s)tatus inconsistency can be defined as the dissimilar ranking on different dimensions of stratification. It deals with the horizontal or nonvertical aspects of stratification."

The general point of status inconsistency theory is that status incongruence causes stress for those in the position of incongruence. As formulated by Lenski (1954:412)

(A)pparently the individual with a poorly crystallized status is a particular type of marginal man, and is subjected to certain pressures by the social order which are not felt (at least to the same degree) by individuals with a more highly crystallized status.

Geschwender (1967:170) argues that status inconsistency may bring about at least five types of "emotional reactions:" 1) anger; 2) guilt; 3) definitions of failure; 4) definitions of success; and 5) ambiguity. House and Harkins (1975) also point out that status inconsistency should be closely related to this notion of emotional stress; however, they observe that this link has yet to be empirically tested.

More pertinent to our concerns is the statement by House and Harkins (1975) that age is a highly relevant variable as regards the matter of status inconsistency. They suggest that as the individual ages, inconsistency becomes more of a problem to deal with, since due to increased age the hopes of eliminating incongruence diminish.

Following House and Harkins (1975), it is suggested that the inconsistent status of the old White would seem to place the White elder in a stressful position, whereas, the consistency of the statuses held by the aged Black would not indicate stress of this nature. The old Black may well be in a position of stress due to his/her low status but the addition of a second, consistent status would not appear to add to this stress, at least within the framework of this theory.

Hence, a balance may be struck between the aged Black and aged White. The Black is in a position of stress to begin with and this remains stable into old age. The old White moves into a situation of stress from a situa- 
tion of stability. Thus, although their social worlds may be somewhat different, they share a similar disability-social stress. As an outgrowth of this status convergence, there would appear to be balance instead of double jeopardy for old Blacks. The aged Black has remained basically stable and the old White has lost status. Ergo, it does not appear from this theoretical perspective that one would predict multiplicative double jeopardy for elderly Blacks.

Social learning and exchange theory

No attempt will be made to explicate the theories of social exchange or social learning except to say that in each case the theory deals with rewards-reinforcers, costs-punishments, and their relationship to human interaction. Each of these theories is grounded upon the belief that behavior is directly related to reinforcement contingencies and that an individual's status or power is a function of the resources one has at hand that enable him/her to form contingencies which are beneficial to one's self.'

Blau (1964) states that if one cannot reciprocate in an exchange relation with equally needed resources, he/she is in a position of dependence. In this position, the dependent actor may use one of four general classes of rewards: 1) money; 2) social approval; 3) esteem; or 4) compliance. Money is considered the least valuable of these generalized rewards followed in ascending order by social approval, esteem, and compliance, respectively. Dowd (1975:587) quotes Blau as stating that whoever "commands services others need, and who is independent of any at their command, attains power over others by making the satisfaction of their need contingent on their compliance." Dowd's emphasis is that the exchange relationship between the broader society and those elderly within it takes a form very similar to the above. He goes on to nöte that:

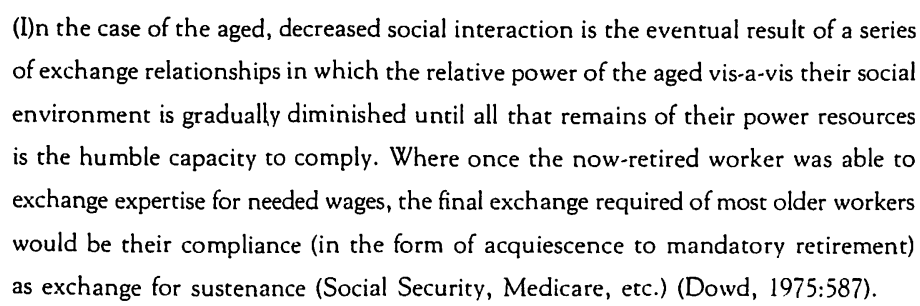

This is important in that it indicates a drop in power and prestige for the older individual, and hence, a feeling of loss. Now, this feeling of loss would logically seem to be mediated by the amount of power lost. Those who have the most to lose would reasonably seem to be the ones most affected by the loss, and since in many cases Blacks have very little social prestige to begin with, it can be argued that they would probably be least affected by this turn of events. Generally speaking, the elderly White, on the other hand, may have moved from a position of relatively high social prestige to one considerably lower. Hence, he/she experiences a noticeable drop in exchange power compared to Blacks. Once again, if this is in fact the case, a prediction of multiplicative double jeopardy for old Blacks does not seem warranted.

With respect to the learning theory approach, Hollon and Beck $(1979: 165)$ report that " $(t)$ he removal of discriminative stimuli for responsereinforcer sequences" is an important factor associated with the onset of depression. When an individual retires, in most cases he/she loses an attribute which has probably been used by ego (self) and alter (other) most of ego's life as a discriminative stimuli. One's employment status (antecedent stimulus) allows others as well as self to construct expectations regarding one's position in society as well as his/her set of abilities (behavior), which further allows ego and alter to behave toward each other with much less ambiguity (reinforcement).

They go on to point out that job loss is " . . an obvious instance of change in the reinforcement potential of the environment" (Hollon and Beck, 1979:165). One can extrapolate from the reinforcement potential of the environment to the idea that the more significant the reinforcement potential (the larger the amount of reinforcement) which is lost, the greater the negative punishment the person will feel for having lost it. ${ }^{3}$ They further report that one applicable interpretation in these circumstances is that "reduced-reinforcement-leads-to-negative model" (Hollon and Beck, 1971:165). Once again, drawing on their work, it seems obvious that the greater the reinforcement lost the more negative mood produced.

This would seem to point out that those with highly reinforcing employment have a better chance of experiencing some sort of negative feelings when that form of reinforcement is removed from their environment than do those with employment having low reinforcement potential. (However, should those individuals with high reinforcement potential be allowed to remain somehow connected to their previous employment, this may not occur.) Simons and West (1980) have argued along similar lines that status loss is related to occupational prestige. They point out that this type of status may act as a leveler in old age. It follows that since the aged White is on 
the average of higher occupational status, he/she presumably loses more than the aged Black. Hence, one can posit the contention that in general, older Whites face a greater probability of having to deal with some sort of depression (negative mood) than do elderly Blacks, since in general, aged Blacks do not lose as significant a reinforcer upon retirement. Botwinick (1978:31), while discussing the higher rate of suicide for aged White males than any other age-race category notes:

. . . that feelings of inferiority and loss of self-esteem are among the major causes of depression in the elderly.... (p)erhaps it may be speculated that this is the price many aged White men pay for opportunities achieved, never realized, or lost. It is interesting to speculate further that women and non Whites of both sexes, having been deprived of opportunities, lose less in later life; in any event, they may not feel as personally unable and unworthy when without high social roles.

Once more we find little support for the multiplicative double jeopardy concept. Expanding on Botwinick (1978), it appears that loss of reinforcement is related to depression which is, in turn, correlated with suicide. Because of greater loss of reinforcers, the old White male is in a rather precarious position, which does not seem to be the case for male or female Blacks. Thus, at least in terms of suicide, in old age the male Black is actu ally better off than his White counterpart and the same holds true for Black females compared to White females. ${ }^{4}$

\section{Status generalization theory}

Berger et al. $(1972 a, 1972 b, 1974,1977)$ have formulated a theory dealing with the manner in which status characteristics are generalized and used as a basis for constructing expectations about self and others' general abilities. They have also noted that certain statuses (which they have referred to as "diffuse" in nature) have a "halo-effect." This notion of a "halo-effect" refers to the circumstance that if $\mathrm{P}$ (person) is ranked on some status, this ranking will have effects in interaction situations even when there is little reason to assume any direct relationship between the status characteristics and the situation at hand. Hence, P's status characteristics are directly related to the expectations formed relative to ego and alter, regardless of the situation, unless there is some indirect evidence to contradict its use (what they have termed "burden of proof"). Further, Webster and Driskell (1978) have reported that in situations where there are multiple status characteristics used to form an expectation status, those doing the expectation construc- tion will tend to combine the statuses to form what might be considered a status average.

This is important since it can be seen that if one has two status characteristics of similar ranking (in this case two negatively ranked status characterizations for the elderly Black) there is no change in status rank. One simply remains in the same social position. On the other hand, if one brings into the situation two status characteristics that are not similar in their status rank, this combination process will in one way raise the status of $\mathrm{P}$ and in one way lower P's status, ergo, placing the actor on a somewhat ambiguous middle ground (in our case this would refer to the elderly White).

This is quite similar to the aforementioned status inconsistency theory. In regard to the positioning of the actor, it can be seen that for the Black elder, the age status does little to affect his/her relative status ranking. In contrast, among White elders the effect of the age status characteristics is to lower his/her status value. This lowered status value also affects the expectation status associated with aged Whites, changing them from a general ranking of relatively high ability to that of a lower ranking.

Harris (1976) argues along similar lines using Goffman's (1963) concept of "spoiled identity." He attempts to establish the notion that one is unable to lose much if one's position (in what he defines as a caste) precludes one's ability to make gains along the lines of achieved statuses. Therefore, if the actor is already a member of a negatively evaluated caste (Black race) his/her identity is already spoiled in many respects and the addition of further negatively evaluated statuses has little effect. For example, Harris (1976) finds this to be true for criminal offenses, where being labeled a deviant is less debilitating for the Black than for the White.

This is pertinent here since it points out the differential effects of à constant status such as race versus a variable status such as age. Following Harris, one sees that race enters into one's status ranking early in life and remains fairly stable throughout the actor's life. Age, on the other hand, has differing effects depending upon the stage of the life cycle of the particular individual. Race (at least in American society) does seem to act in similar manner to a caste and will effect an individual's social position and reactions to changes such as aging. The Black, typically on the lower rungs of the status ladder in American society is, in some ways, insulated from the effects of multiple negative status evaluations. The White, however, has much to lose since his/her position has been one of relatively high standing as compared to Blacks and any negative statuses accruing to his/her self-conception will take the form of an identity spoiler. 


\section{CONCLUDING REMARKS AND DISCUSSION}

In summary, based on the theories discussed there is little support for the multiplicative double jeopardy concept. However, although the theories do appear to have some degree of epistemic correlation to the concept at hand, we can make no certain predictions without actually testing the phenomenon. It may well be that, in this specific instance, these theories do not hold. Indeed, the impact of age may be such that it does add to the negative position of Blacks regardless of what these theories predict. Yet, the theoretical frameworks presented above do inform the researcher of possible alternative outcomes. They serve to add insight to situations that otherwise would appear to be straightforward; and by denoting the underlying complexity of such a seemingly simple conception of multiple status characteristics, they allow us to deal with the phenomenon at a more sophisticated level.

Had previous researchers attempted to be more systematic in focusing on some of the theoretical dimensions of double jeopardy, many of the scope conditions of this concept may well have been sorted out by now. This lack of theoretical grounding is seen as an overall shortcoming of much research in this area of aging and it is hoped that this deficiency can be overcome in future research programs.

Finally, it is very important to state that this study has dealt with the notion of double jeopardy as a multiplicative function of age and race. However, this is only one way of defining the concept. In fact, the concept is also defined as an additive function by some of the researchers in the field. This difference in definition is an important qualifier, in that one's findings will most assuredly be affected by how one operationalizes the double jeopardy concept. Social researchers need to form a consensus about how to define double jeopardy or this concept may become too amorphous to be useful.

\section{ENDNOTES}

1. Note, however, that this may be due to restricted mobility rather than familial affinity.

2. It should be pointed out that there is certain amount of discord with respect to the usefulness of this theory. Yet Strieb (1976) has argued that it is a useful concept in the area of aging and stratification. Even though there is uncertainty, as indicated earlier, this will not concern us here, for we are not testing the theory but are simply using it for its heuristic value.

3. A negative punishment has the effect of decreasing behavior of one type by removing a positive reinforcer from the actor.

4. As an aside, there is a literature which formulates the notion that previous stress brings about coping abilities and hence, the black elder, having dealt with stressful situations throughout life has built up a more well-formed set of coping abilities than the old white and is thereby better prepared for the stress of old age.

\section{REFERENCES}

Bengtson, $\mathrm{V}$.

1977. "Ethnicity and Perceptions of Aging." Paper presented at the conference on aging: A Challenge to science and social policy. Vichy, France.

Berger, J., M. Zelditch, B. Anderson, and B. Cohen

1972a "Structural Aspects of Distributive Justice: A Status Value Formulation." Chapter six in J. Berger, M. Zelditch, and B. Anderson (eds.), Sociological Theories in Progress. New York: Houghton Mifflin

Berger, J., T. Conner, and M.H. Fisek

1974 Expectation States Theory: A Theoretical Research Program. Cambridge: Winthrop Publishers, Inc.

Berger, J. B. Cohen, and M. Zelditch

1972b "Status Characteristics and Social Interaction." American Sociological Review 37:241-55. Berger, J., M. H. Fisek, R. Norman, and M. Zelditch

1977 Status Characteristics and Social Interaction: An Expectation-States Approach. New York:

Blau, P.

1964 Exchange and Power in Social Life. New York: John Wiley and Sons.

1964 Exchange and Power in Social Life. New York: John Wiley and Sons. 
Botwinick, J.

1978 Aging and Behavior. New York: Springer Publishing.

Chappell, N., and B. Havens

1980 "Old and Female: Testing the Double Jeopardy Hypothesis." The Sociological Quarterly 21:157-71.

Cogwill, D.

1974 "The Aging of Populations and Societies." The Annuals of the American Academy of Political and Social Science 415:1-18.

Coon, $\mathrm{R}$

1978 Status Characteristics and Expectation States: The Hour Glass Effect of Aging. Unpublished Master's Thesis, University of Wyoming.

Cooper, T. and M. Simonin

1978 Ad Hoc Report - Age and Ethnic Differences in Attitudes Toward Death. Project M.A.S.P. (Minority Aging and Social Policy) Andrus Gerontology Center, University of Southern California, Los Angeles.

Dowd, J.

1975 "Aging as Exchange: A Preface to Theory." Journal of Gerontology30:584-94.

Dowd, J. and V. Bengtson

1978 "Aging in Minority Populations: An Examination of the Double Jeopardy Hypothesis." Journal of Gerontology 33:427-36

Elam, L

1970 "Critical Factors for Mental Health in Aging Black Populations." Paper presented at the workshop on Ethnicity, Mental Health, and Aging, Los Angeles, California.

Ewen, S.

1976 Captains of Consciousness. New York: McGraw-Hill.

Fischer, D.

1978 Growing Old in America. Oxford: Oxford University Press.

Geschwender, J.

1967 "Continuities in Theories of Status Consistency and Cognitive Dissonance." Social Forces 46:160-71.

Goffman, E.

1963 Stigma. Englewood Cliffs, New Jersey: Prentice-Hall.

Harris, A.

1976 "Race, Commitment to Deviance, and Spoiled Identity." American Sociological Review 41:432-42.

Harris, D. and W. Cole

1980 Sociology of Aging. Boston: Houghton Mifflin.

Hill, R.

1978 "A Demographic Profile of the Black Elderly." Aging 287-88:4-5

Hollon, S. and A. Beck

1979 "Cognitive Therapy of Depression" Chapter six in P. Kendall and S. Hollon (eds.) Cognitive-Behavioral Interventions: Theory, Research and Procedures. New York: Academic Homans, G. Press.

1974 Social Behavior: lts Elementary Forms. New York: Harcourt Brace Jovanovich

Hornung, C.

1977 "Social Status, Status Inconsistency and Psychological Stress." American Sociological Review 42:623-38.

House, J. and E. Harkins

1975 "Why and When Is Status Inconsistency Stressful?" The American Journal of Sociology $81: 395-412$
Hughes, E.

1945 "Dilemmas and Contradictions of Status." The American Journal of Sociology 50:853-59.

Jackson,

1970

"Aged Negroes: Their Cultural Departures from Statistical Stereotypes and Rural-Urban Differences." Gerontologist 10:140-45.

1972 "Marital Life Among Aging Blacks." Family Coordinator 21:21-27.

1974 "NCBA, Black Aged, and Politics." In F. Eisele (ed.), Political Consequence of Aging. Annals of the American Academy of Political and Social Science 415:138-59.

Jackson, J. and B. Walls

1978 "Myths and Realities About Aged Blacks." In M. Brown (ed.), Readings in Gerontology St. Louis: C.V. Moby.

Kalish, R.

1975 Late Adulthood: Perspectives on Human Development. Monterey: Brooks/Cole.

Kent, D.

1971 "Changing Welfare to Serve Minority Aged." Minority Aged in America, Institute of Geron tology, the University of Michigan - Wayne State University.

Lenski, G.

954 "Status Crystallization: A Nonvertical Dimension of Social Status." American Sociological Review 19:405-413.

Lynd, R. and H. Lynd

1929 Middletown: A Study in Contemporary American Culture. New York: Harcourt, Brace and Company.

Marshall, V.

1976 "Socialization for Impending Death in a Retirement Village." In C. Kart and Manard (eds.), Aging in America. Port Washington: Alfred Publishing.

Merton, R.

1968 Social Theory and Social Structure. New York: The Free Press.

Moore, J.

1971 "Situational Factors Affecting Minority Aging." The Gerontologist 11:88-93.

National Urban League

1964 Double Jeopardy, the Older Negro in America Today. New York: National Urban League. Neugarten, B. and J. Moore

1968 "The Changing Age-Status System." In B. Neugarten (ed.), Middle Age and Aging. Chicago: The University of Chicago Press.

Palmore, E. and K. Manton

1973 "Ageism Compared to Racism and Sexism." Journal of Gerontology 3:363-69.

Pampel, Fred

1981 Social Change and the Aged. Lexington: Lexington Books.

Ragan, $\mathrm{P}$

1978 Ethnic and Racial Variation in Aging: Implications for Social Policy and Service Delivery.

Seelbach, W.

1978 "Correlates of Aged Parents' Filial Responsibility Expectation and Realizations." The Family Coordinator 27:341-50.

Simons, R., and G. West

1980 "Life Changes, Coping Resources and Health Among the Elderly." Unpublished paper.

1976 "Social Stratification and Aging." In R. Binstock and E. Shanas (eds.), Handbook of Aging and the Social Sciences. New York: Van Nostrand Reinhold. 


\section{BOOK REVIEWS}

Ward, Russell

1979 "The Stability of Racial Differences Across Age Strata: An Assessment of Double Jeopardy." Paper presented at the 32nd Annual Meeting of the Gerontological Society, Washington.

Webster, M. and J. Driskell

1978 "Status Generalization: A Review and Some New Data." American Sociological Review 43:220-36.
Eva Spangler, Lawyers for Hire: Salaried Professionals at Work, New Haven: Yale University Press, 1986. 245 Pp. $\$ 25.00$ (cloth).

In Lawyers for Hire, Eva Spangler offers an in-depth analysis of how shifts from "free professional" to salaried status is effecting changes in the structure of and control over the work of the lawyer, the ramifications of such changes for the lawyers' professional life, and the implications of such changes for the rest of society. She prefaces her discussion by demonstrating that, in a move away from the traditional patriarchal type of law firm that operates with a powerful senior partner who delegates little power in maintaining control over the firm, an increasing number of lawyers have come to work as salaried employees in large firms and other work environments which manifest the characteristics associated with bureaucratic organizations. Positing the hypothetical "professional-bureaucratic conflict" which assumes inherent conflict between professionalism and bureaucracy, she sets out to explore the ways in which attorneys are required to conform to organizational demands. New findings obtained through more than 100 interviews with staff lawyers in large law firms, corporate, governmental, and legal aid settings in the New England area are analyzed by addressing issues regarding how these lawyers organize their work in balancing accountability to an employer with both professional judgment and their clients' interests. Other issues addressed include the possibilities of the salaried attorney becoming de-skilled, the increasing trend toward specialization, and how the two may be related.

Spangler dèvơtes one chapter each to salaried attorneys in four diverse settings presented in the following order: associates in large law firms (75 or more lawyers); house counsel in business corporations; attorneys in various branches of government; and attorneys who work for local affiliates of the Legal Services Corporation ( $\mathrm{a} / \mathrm{k} / \mathrm{a}$ "Legal Aid"). As the type of attorney with which we are most familiar, associates in large law firms are descriptively distinguished from those with memberships in traditional law firms. This informative profile is then used as a basis for making comparisons to and contrasts with corporate house counsel. Both analyses then serve as bases for discussing the two types of civil service attorneys: those who represent the government itself, and those who provide services for indigent citizens. Throughout the book, Spangler relies heavily on the professionals 